\title{
Improved Detection of Scaphoid Fractures with High- Resolution Peripheral Quantitative CT Compared with Conventional CT
}

Citation for published version (APA):

Daniels, A. M., Bevers, M. S. A. M., Sassen, S., Wyers, C. E., van Rietbergen, B., Geusens, P. P. M. M., Kaarsemaker, S., Hannemann, P. F. W., Poeze, M., van den Bergh, J. P., \& Janzing, H. M. J. (2020). Improved Detection of Scaphoid Fractures with High-Resolution Peripheral Quantitative CT Compared with Conventional CT. Journal of Bone and Joint Surgery, 102(24), 2138-2145.

https://doi.org/10.2106/JBJS.20.00124

Document status and date:

Published: 16/12/2020

DOI:

10.2106/JBJS.20.00124

Document Version:

Publisher's PDF, also known as Version of record

Document license:

Taverne

Please check the document version of this publication:

- A submitted manuscript is the version of the article upon submission and before peer-review. There can be important differences between the submitted version and the official published version of record.

People interested in the research are advised to contact the author for the final version of the publication, or visit the DOI to the publisher's website.

- The final author version and the galley proof are versions of the publication after peer review.

- The final published version features the final layout of the paper including the volume, issue and page numbers.

Link to publication

\footnotetext{
General rights rights.

- You may freely distribute the URL identifying the publication in the public portal. please follow below link for the End User Agreement:

www.umlib.nl/taverne-license

Take down policy

If you believe that this document breaches copyright please contact us at:

repository@maastrichtuniversity.nl

providing details and we will investigate your claim.
}

Copyright and moral rights for the publications made accessible in the public portal are retained by the authors and/or other copyright owners and it is a condition of accessing publications that users recognise and abide by the legal requirements associated with these

- Users may download and print one copy of any publication from the public portal for the purpose of private study or research.

- You may not further distribute the material or use it for any profit-making activity or commercial gain

If the publication is distributed under the terms of Article $25 \mathrm{fa}$ of the Dutch Copyright Act, indicated by the "Taverne" license above, 


\title{
Improved Detection of Scaphoid Fractures with High-Resolution Peripheral Quantitative CT Compared with Conventional CT
}

A.M. Daniels, MD, M.S.A.M. Bevers, MSc, S. Sassen, MD, C.E. Wyers, PhD, B. van Rietbergen, PhD, P.P.M.M. Geusens, MD, PhD, S. Kaarsemaker, MD, P.F.W. Hannemann, MD, PhD, M. Poeze, MD, PhD, J.P. van den Bergh, MD, PhD, and H.M.J. Janzing, $\mathrm{MD}, \mathrm{PhD}$

Investigation performed at VieCuri Medical Centre, Venlo, the Netherlands

\begin{abstract}
Background: Computed tomography (CT), magnetic resonance imaging, and bone scintigraphy are second-line imaging techniques that are frequently used for the evaluation of patients with a clinically suspected scaphoid fracture. However, as a result of varying diagnostic performance results, no true reference standard exists for scaphoid fracture diagnosis. We hypothesized that the use of high-resolution peripheral quantitative CT (HR-pQCT) in patients with a clinically suspected scaphoid fracture could improve scaphoid fracture detection compared with conventional CT in the clinical setting.
\end{abstract}

Methods: The present study included 91 consecutive patients ( $\geq 18$ years of age) who presented to the emergency department with a clinically suspected scaphoid fracture between December 2017 and October 2018. All patients were clinically reassessed within 14 days after first presentation, followed by CT and HR-pQCT. If a scaphoid fracture was present, the fracture type was determined according to the Herbert classification system and correlation between $\mathrm{CT}$ and HR-pQCT was estimated with use of the Kendall W statistic or coefficient of concordance (W) (the closer to 1, the higher the correlation).

Results: The cohort included 45 men and 46 women with a median age of 52 years (interquartile range, 29 to 67 years). HR-pQCT revealed a scaphoid fracture in 24 patients (26\%), whereas CT revealed a scaphoid fracture in 15 patients (16\%). Patients with a scaphoid fracture were younger and more often male. The correlation between CT and HR-pQCT was high for scaphoid fracture type according to the Herbert classification system ( $\mathrm{W}=0.793 ; 95 \%$ confidence interval [Cl], 0.57 to $0.91 ; p<0.001)$ and very high for scaphoid fracture location $(\mathrm{W}=0.955 ; 95 \%, \mathrm{Cl} 0.90$ to $0.98 ; \mathrm{p}<0.001)$.

Conclusions: In the present study, the number of patients diagnosed with a scaphoid fracture was $60 \%$ higher when using HR-pQCT as compared with CT. These findings imply that a substantial proportion of fractures-in this study, more than one-third - will be missed by the current application of CT scanning in patients with a clinically suspected scaphoid fracture.

Level of Evidence: Diagnostic Level II. See Instructions for Authors for a complete description of levels of evidence.

$\mathrm{T}$ 1 he scaphoid bone is the most commonly fractured carpal bone. Scaphoid fractures represent $2 \%$ to $6 \%$ of all fractures and occur mainly in young and active patients 15 to 40 years of age. In the Netherlands, scaphoid fractures account for $90 \%$ of all carpal fractures ${ }^{1-4}$. The scaphoid bone articulates with 5 surrounding bones and therefore serves a key role in the function of the wrist ${ }^{5}$. Inadequate treatment of a scaphoid fracture can lead to malunion, nonunion, and early osteoarthritis ${ }^{1,6,7}$. These complications are associated with pain, decreased range of motion, reduced grip strength, and worse functional outcome. Consequently, early and accurate diagnosis is important. As up to $25 \%$ of scaphoid fractures remain radiographically occult with conventional imaging ${ }^{1,8-10}$, patients with a suspected scaphoid fracture are generally managed with cast immobilization, and reassessment takes place after approximately 10 days, resulting in a diagnostic delay of up to 2 weeks. According to the existing literature, only $10 \%$ to $20 \%$ of clinically suspected fractures are true fractures ${ }^{4,8,11-14}$. This implies

Disclosure: The authors indicated that no external funding was received for any aspect of this work. On the Disclosure of Potential Conflicts of Interest forms, which are provided with the online version of the article, one or more of the authors checked "yes" to indicate that the author had a relevant financial relationship in the biomedical arena outside the submitted work (http://links.Iww.com/JBJS/G169). 
The Journal of Bone \& Joint Surgery - JBjs.org Volume 102-A - Number $24 \cdot$ December 16,2020
Improved Detection of Scaphoid Fractures with HR-pQCT Compared With Conventional CT that most patients are overtreated, with unnecessary socioeconomic effects, as result of cast immobilization.

Radiographic diagnosis of scaphoid fractures is difficult because of the unique shape, size, and orientation of this carpal bone. Various imaging techniques have been suggested for the improvement of diagnosis and the reduction of overtreatment. Computed tomography (CT), magnetic resonance imaging (MRI), and bone scintigraphy (BS) are most frequently used today, but all have limitations $s^{11-13,15-24}$. None of the investigated diagnostic modalities is both sensitive and specific, and therefore no true reference standard exists. Despite advanced knowledge and imaging methods, diagnosing scaphoid fractures remains challenging, and the preferred imaging technique differs according to hospital. The technique used at the hospital involved in the present study is CT.

The development of high-resolution peripheral quantitative CT (HR-pQCT), a novel high-resolution and lowradiation-dose technique, allows for the assessment of cortical and trabecular bone microarchitecture at the distal parts of the radius and tibia ${ }^{25,26}$. Recent research has shown that studying the fracture-healing process of stable distal radial fractures ${ }^{27,28}$ and scanning the scaphoid bone in patients with a clinically suspected scaphoid fracture are feasible with HR-pQCT ${ }^{29}$. We hypothesized that the use of HR-pQCT for patients with a clinically suspected scaphoid fracture would improve scaphoid fracture detection when compared with conventional CT in the clinical setting.

\section{Materials and Methods}

$\mathrm{T}$ he present study was approved by the medical ethics committee (NL 62476.068.17) and was conducted according to the principles of the Declaration of Helsinki and in accordance with the Medical Research Involving Human Subjects Act (WMO).

\section{Study Population}

For the present study, all patients with a clinically suspected scaphoid fracture presenting to the emergency department within 1 week after trauma were screened for eligibility. Pregnant women and patients with a previous ipsilateral scaphoid fracture were excluded. Between December 2017 and October 2018 , a total of 91 patients $\geq 18$ years of age were enrolled in our study (Fig. 1). In the emergency department, conventional radiographs were made in 4 views: posteroanterior, true lateral, semipronated oblique, and posteroanterior with the wrist in ulnar deviation. Independent of the diagnosis on these initial radiographs, cast immobilization was applied until the definite diagnosis was obtained. All patients, regardless of the findings on the initial radiographs, received written information on the study from their treating physician in the emergency department and were, after granting permission, contacted by telephone within the next 4 days by the investigator to answer any remaining questions that they had regarding the study. CT and HR-pQCT were scheduled immediately following reassessment in the outpatient clinic. According to current clinical practice, this reassessment was performed within 7 to 14 days after trauma. Informed consent was obtained during this visit and was followed by physical examination, questionnaires, CT, and HR-pQCT. Medical history, smoking status, alcohol use, medication use, hand dominance, and trauma mechanism were registered.

\section{CT Scanning}

$\mathrm{CT}$ of the affected forearm was performed with use of the SOMATOM Definition AS (Siemens). This scanner contains an $80-\mathrm{kW}$ generator and Ultra-Fast Ceramics detector with a rotation time of 1 second (tube voltage, $120 \mathrm{kV}$; tube current range, $35 \mu \mathrm{A}$; pitch, 0.6; 128 slices; slice thickness, $1.0 \mathrm{~mm}$; slice increment, $0.5 \mathrm{~mm}$ ). The effective radiation dose of $1 \mathrm{CT}$ scan of the hand and wrist is $46 \mu \mathrm{Sv}$. All scans were conducted with the wrist in a fiberglass cast. According to the local protocol, all scans were reconstructed in the transverse, coronal, and sagittal planes of the wrist. In cases in which no fracture was detected on the 3 conventional reconstructed planes, reconstruction in the plane of the scaphoid was obtained. CT images were uploaded into IMPAX Client software (AGFA).

\section{HR-pQCT Scanning}

Second-generation HR-pQCT (XtremeCT II; Scanco Medical AG) was used to scan the affected forearm. All scans were conducted with the wrist in a fiberglass cast with a detachable fiberglass cast around the thumb, which was only applied during the HR-pQCT procedure for added stability of the thumb. The forearm was placed into an anatomically shaped holder to obtain a standardized position. On the basis of a scout view, the region of interest was determined, and a reference line was placed on the rim at the joint surface of the distal part of the radius. The standard scan protocol of the distal part of the radius, with an isotropic voxel size of $0.061 \mathrm{~mm}$, was adapted to 3 consecutive stacks of $10.2 \mathrm{~mm}$, resulting in a scanned region of $30.6 \mathrm{~mm}$ to cover the entire scaphoid bone. The effective radiation dose of HR-pQCT scanning of the scaphoid is $15 \mu \mathrm{Sv}$. The maximum dose to which patients were exposed was $30 \mu \mathrm{Sv}$ when repetition of the scan was necessary because of motion artifacts (grade- 4 to 5) ) $^{30-33}$, which were graded according to the manufacturer's protocol and the method of Pialat et al. ${ }^{32}$. In the present study, all scans were considered to be of acceptable quality for fracture assessment, including 3 scans that had grade- 4 quality in only 1 of the 3 stacks. Scans were exported in Digital Imaging and Communications in Medicine (DI$\mathrm{COM}$ ) format. Source images were reconstructed into transverse, coronal, and sagittal planes. All HR-pQCT images and reconstructions were anonymized and uploaded to the local workstation.

\section{Scan Evaluation}

All CT scans were evaluated by a radiologist (within 48 hours) and a dedicated hand and wrist orthopaedic trauma surgeon (within 1 week); both were blinded to the other's assessment of the patients as well as to their clinical data. They were asked to state the type of fracture (i.e., scaphoid, distal radial, carpal) on the basis of their expert opinion and to classify the scaphoid 
The Journal of Bone \& Joint Surgery $\cdot$ JbJs.org Volume 102-A - Number $24 \cdot$ December 16,2020
Improved Detection of Scaphoid Fractures with HR-pQCT

Compared with Conventional CT

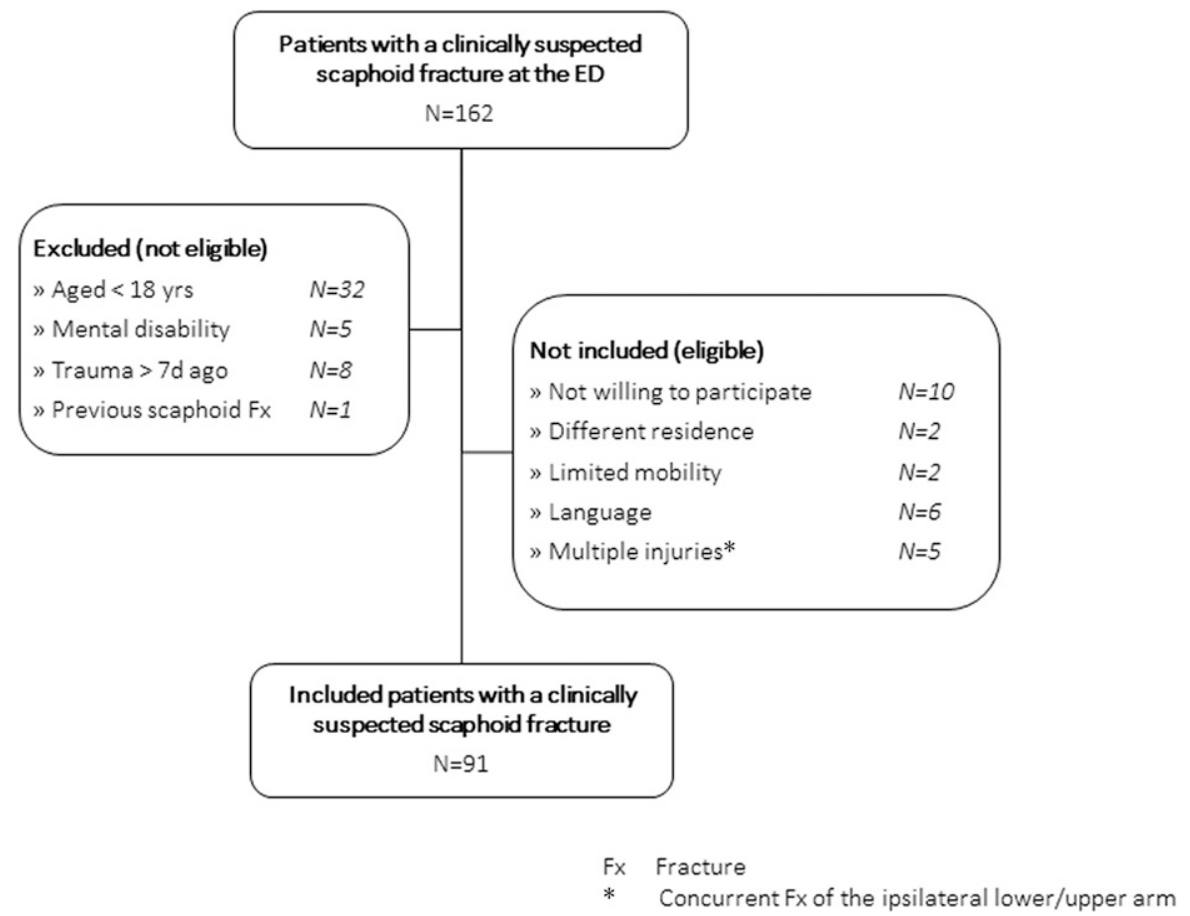

Fig. 1

Flowchart illustrating inclusion and exclusion of patients with a clinically suspected scaphoid fracture at the emergency department (ED).

fracture, if present, according to the Herbert classification system (Fig. 2) ${ }^{34}$. Additional assessment by a third investigator was used for scans with a discrepant judgment by the 2 observers $(n=4)$. The subsequent decision regarding diagnosis was based on majority assessment.

All HR-pQCT scans were evaluated by a musculoskeletal radiologist. In a previous study, the interobserver agreement for 4 observers ( 2 musculoskeletal radiologists and 2 orthopaedic trauma surgeons) was shown to be almost perfect regarding scaphoid fracture diagnosis with HR-pQCT in patients with a clinically suspected scaphoid fracture ${ }^{35}$. The observers evaluated each HR-pQCT scan independently and were asked to determine the presence of a scaphoid fracture or other fracture (i.e., distal radial, carpal, metacarpal) on the basis of their expert opinion and to classify the scaphoid fracture, if present, according to the Herbert classification system (Fig. 2) ${ }^{34}$. The observers were aware of the fact that all patients were clinically suspected of having a scaphoid fracture on the basis of physical examination in the emergency department. All observers were blinded to the diagnosis on

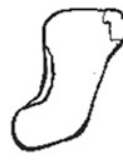

A1

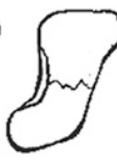

A2

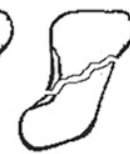

B1

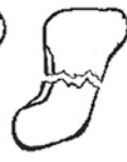

B2

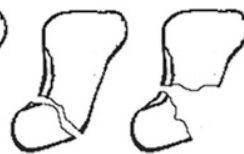

B3

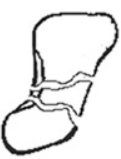

B5
Illustrations depicting the Herbert scaphoid fracture classification system (1984). conventional radiographs and CT and were not aware of the others' assessments. The observers did not have access to any clinical data on the patients.

\section{Statistical Analysis}

Statistical analysis was performed with use of SPSS Statistics (version 24; IBM). The distribution of the data was tested with Q-Q (quantile-quantile) plots and Kolmogorov-Smirnov analysis. Normally distributed data are presented as the mean and the standard deviation (SD). Age was non-normally distributed and therefore is presented as the median with the interquartile range (IQR). Chi-square and independentsample $\mathrm{t}$ tests were used to analyze differences between patients with a fracture (scaphoid or other) and without a fracture. Crosstab calculation with McNemar testing was conducted to compare the proportions of scaphoid fractures diagnosed on CT and HR-pQCT. The correlation between scaphoid fracture classification and location with CT and HRpQCT was estimated with use of the Kendall W statistic or coefficient of concordance (W); the closer to 1, the higher the correlation. Diagnostics performance characteristics were calculated with use of the MedCalc diagnostic test evaluation calculator and are presented as percentages with 95\% confidence intervals (CIs). The level of significance was set at 0.05 .

\section{Results}

\section{Patient Characteristics}

Al patients were reassessed at the outpatient clinic within A 14 days after presentation at the emergency department (median, 10 days; IQR, 6 to 14 days). The cohort consisted of 
TABLE I Distribution of Scaphoid Fracture Incidence by Sex and Age Group for CT and HR-pQCT Diagnosis

\begin{tabular}{|c|c|c|c|c|c|}
\hline & \multicolumn{5}{|c|}{ Scaphoid Fracture (no. [\%] of patients) } \\
\hline \multicolumn{6}{|c|}{ CT $(n=15)$} \\
\hline Men & $5(33.3 \%)$ & $3(20.0 \%)$ & $1(6.7 \%)$ & $1(6.7 \%)$ & $10(66.7 \%)$ \\
\hline Women & $1(6.7 \%)$ & $2(13.3 \%)$ & $1(6.7 \%)$ & $1(6.7 \%)$ & $5(33.3 \%)$ \\
\hline \multicolumn{6}{|c|}{ HR-pQCT $(n=24)$} \\
\hline Women & $3(12.5 \%)$ & $3(12.5 \%)$ & $2(8.3 \%)$ & $1(4.2 \%)$ & 9 (37.5\%) \\
\hline
\end{tabular}

45 men and 46 women with a median age of 52 years (IQR, 29 to 67 years). Men were significantly younger compared with women $(37$ versus 62 years; $\mathrm{p}<0.001)$. On CT, 15 patients with a median age of 41 years (IQR, 22 to 53 years) were diagnosed with a scaphoid fracture. On HR-pQCT, 24 patients with a median age of 44 years (IQR, 35 to 65 years) were diagnosed with a scaphoid fracture. The number and proportion of scaphoid fractures on CT and HR-pQCT according to sex and age are shown in Table I.

\section{Fracture Diagnosis}

In the entire cohort, 1 nondisplaced triquetral fracture was diagnosed on HR-pQCT but not on CT and 6 distal radial fractures were not diagnosed on HR-pQCT because of the restricted scanned region; those fractures were not registered as missed diagnoses.

Nine scaphoid fractures $(37.5 \%)$ that were diagnosed with HR-pQCT were not diagnosed with CT, resulting in a significant difference in the proportion of patients with a scaphoid fracture on CT and HR-pQCT $(\mathrm{p}=0.004)$ (Fig. 3). Figures 4 and 5 demonstrate the CT and HR-pQCT images for 2 patients with a scaphoid fracture that was detected on HRpQCT but not on CT.

Two of the 9 patients in whom a scaphoid fracture was diagnosed on HR-pQCTonly did not want to receive treatment as they experienced no discomfort as a result of the fracture and refused follow-up. The other 7 patients were managed with cast immobilization for at least 6 weeks, as were the patients in whom a scaphoid fracture was diagnosed on both CT and HRpQCT. One of those 7 patients had a concurrent fracture of the hamate that was diagnosed on both CT and HR-pQCT.

There was no significant difference between men and women in terms of median age or between patients with and without a scaphoid fracture (on either CT or HR-pQCT) in terms of trauma mechanism (low-energy, high-energy, or sports/bicycle accidents).

\section{Scaphoid Fracture Classification}

The highest proportions of fracture types according to the Herbert classification system were type A1 on CT (40\%) and type A2 on HR-pQCT (29\%) (Figs. 6-A and 6-B). The most common location was distal on CT $(53 \%)$ and the scaphoid waist on HR-pQCT (46\%) (Figs. 7-A and 7-B). The correlation between CT and HR-pQCT was high for scaphoid fracture type $(\mathrm{W}=0.793 ; 95 \% \mathrm{CI}, 0.57$ to $0.91 ; \mathrm{p}<0.001)$ and very high for scaphoid fracture location ( $\mathrm{W}=0.955 ; 95 \% \mathrm{CI}, 0.90$ to $0.98 ; \mathrm{p}$ $<0.001$ ). There was no significant difference between type-A and B fractures (as diagnosed on both CT and HR-pQCT) in terms of sex, age, or trauma mechanism (low-energy, highenergy, and sports/bicycle accidents).

\section{Fig. 3}
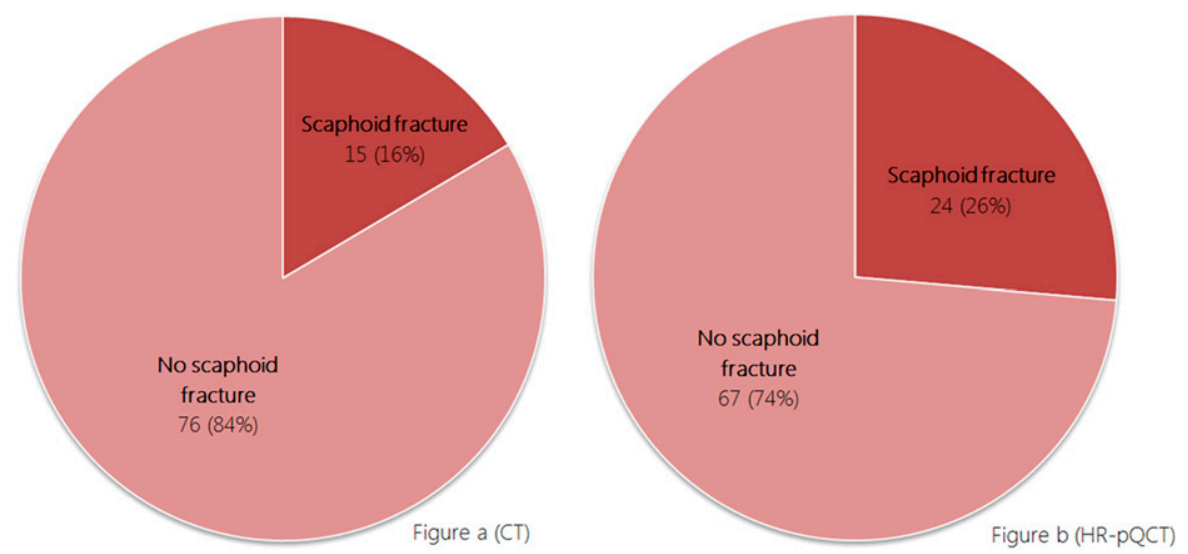

Pie charts showing the rates of scaphoid fracture on CT (Fig. 3-A) and HR-pQCT (Fig. 3-B) $(p=0.004)$. 
The Journal of Bone \& Joint Surgery $\cdot$ JbJS. org Volume 102-A · Number 24 - December 16, 2020
Improved Detection of Scaphoid Fractures with HR-pQCT Compared With Conventional CT

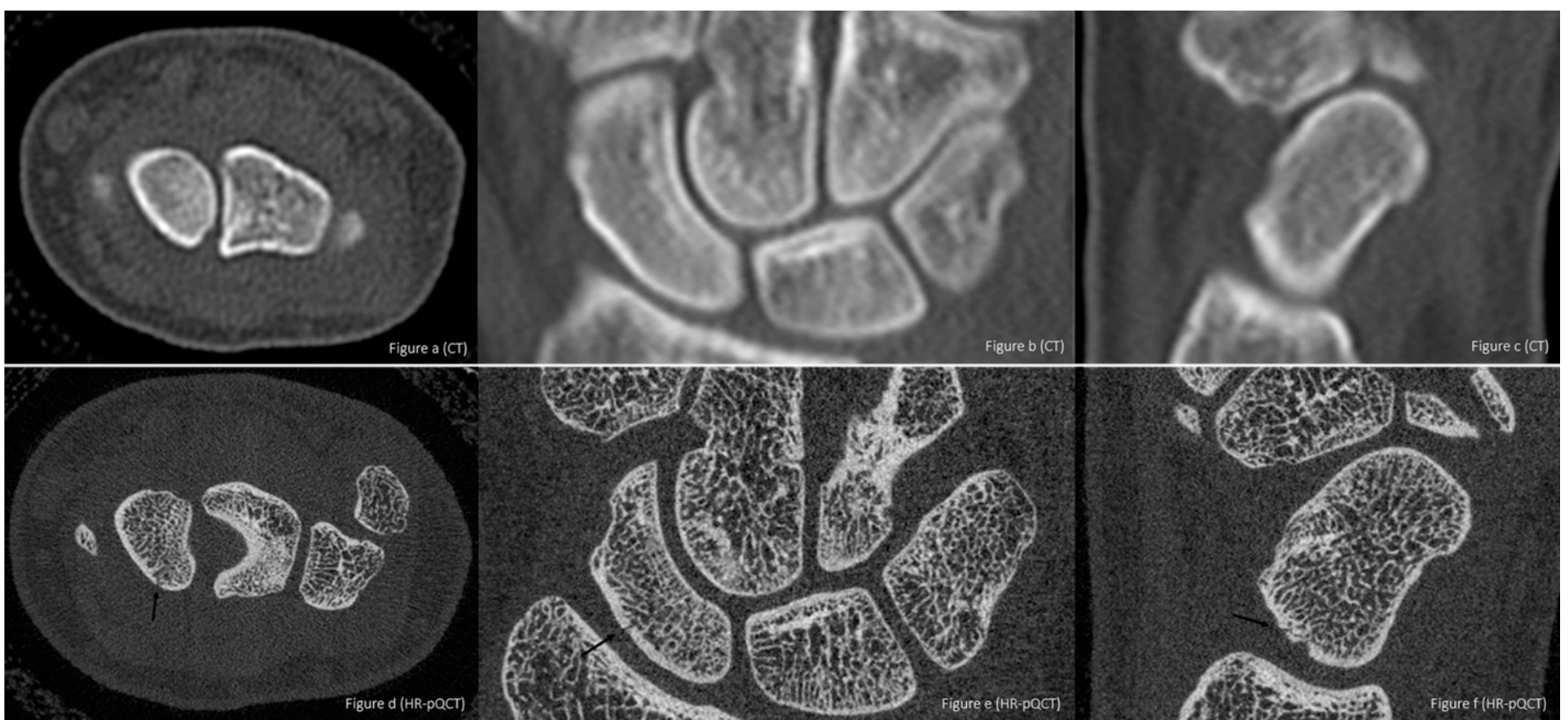

Fig. 4

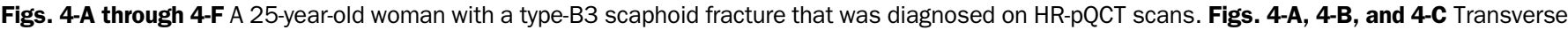

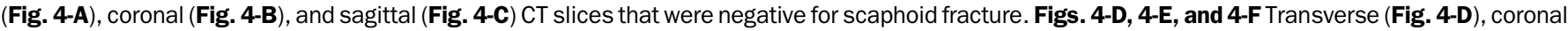
(Fig. 4-E), and sagittal (Fig. 4-F) HR-pQCT scans that were positive for scaphoid fracture (arrows).

\section{Discussion}

To our knowledge, the present study is the first clinical study 1 comparing CT and HR-pQCT for the diagnosis of scaph- oid fractures. Many studies examining the use of CT, MRI, and BS for the diagnosis of such fractures have demonstrated a wide variation in diagnostic performance ${ }^{11,18,21,22,36}$. This variation

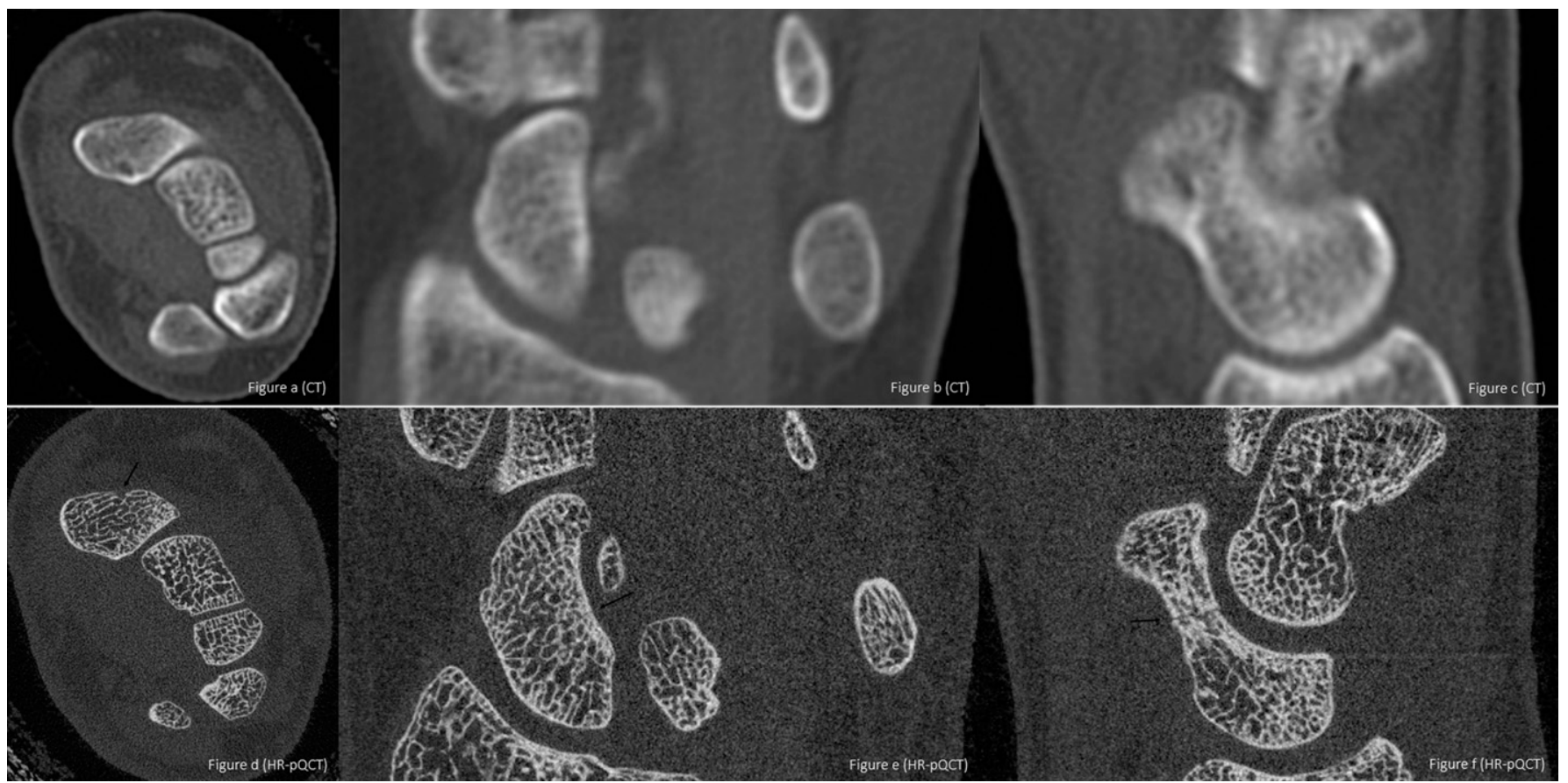

Fig. 5

Figs. 5-A through 5-F A 38-year-old woman with a type-A2 scaphoid fracture that was diagnosed on HR-pQCT scans. Figs. 5-A, 5-B, and 5-C Transverse (Fig. 5-A), coronal (Fig. 5-B), and sagittal (Fig. 5-C) CT slices that were negative for scaphoid fracture. Figs. 5-D, 5-E, and 5-F Transverse (Fig. 5-D), coronal (Fig. 5-E), and sagittal (Fig. 5-F) HR-pQCT scans that were positive for scaphoid fracture (arrows). 
The Journal of Bone \& Joint Surgery - Jbjs. org Volume 102-A · Number $24 \cdot$ December 16, 2020
Improved Detection of Scaphoid Fractures with HR-pQCT Compared With Conventional CT
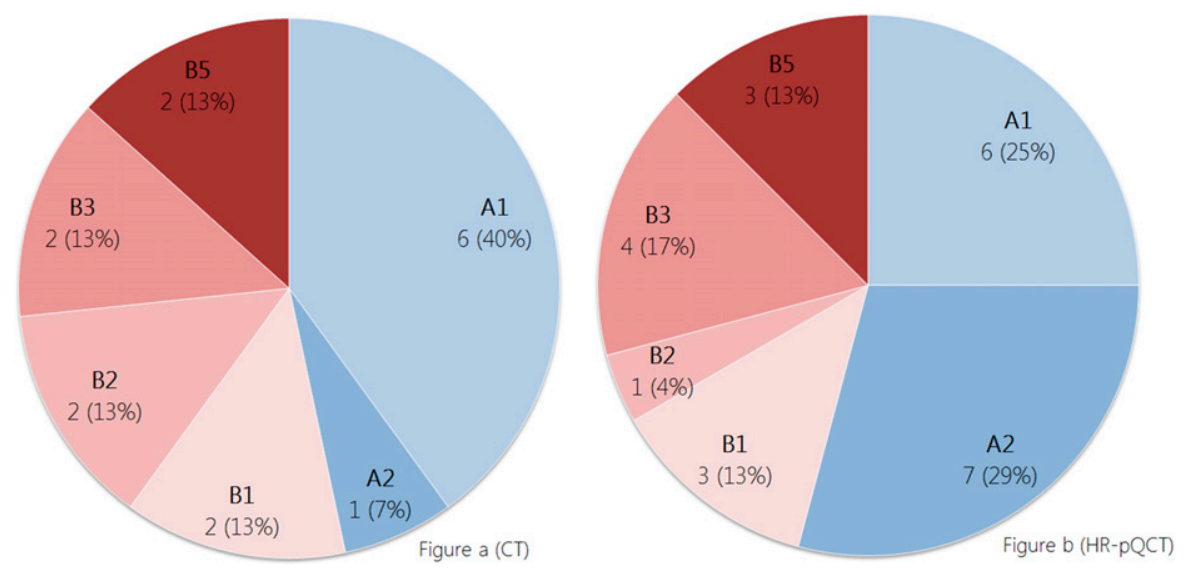

Fig. 6

Pie chart showing the Herbert scaphoid fracture classification on CT (Fig. 6-A) and HR-pQCT (Fig. 6-B) $($ W = 0.793).

might be a result of the low incidence of scaphoid fractures and the use of different scanning protocols. MRI is an appropriate imaging technique to exclude a scaphoid fracture (specificity, $94 \%$ to $100 \%)^{17,20,22,37,38}$. However, MRI is time-consuming, has restricted availability in many hospitals, and is relatively expensive $^{16}$. In contrast, CT is readily available and less expensive. A limitation of CT in diagnosing scaphoid fractures is its relatively low sensitivity compared with MRI and BS and the exposure of patients to radiation ${ }^{11,18,21,36}$. BS has high sensitivity but low specificity ${ }^{17,21,22,37,38}$ and is invasive, is timeconsuming, and leads to a delay in diagnosis of 3 to 5 days. Most studies have used an unreliable method-namely, repeated radiographs after 6 weeks $\mathrm{w}^{22,39-42}$-as the reference standard $^{11,16-18}$. The lack of a universal reference standard makes it difficult to compare the results of previous studies and contributes to the described variation.

Current clinical imaging techniques, as described above, lack the ability to assess bone microarchitecture and thereby separately assess cortical and trabecular bone. A noninvasive method that recently became available for the assessment of bone microarchitecture at the distal parts of the radius and tibia is HR-pQCT ${ }^{43}$. Validation and reproducibility studies of HR-
pQCT have been performed extensively for the distal part of the radius ${ }^{44-47}$, and, in the last decade, widespread experience has been gathered in the use of this technique for clinical research $^{48,49}$. It is conceivable that distinctions between vascular structures, motion artifacts, and fractures are more apparent with this method because of its higher resolution, which may help to improve scaphoid fracture diagnosis. In the present study, the HR-pQCT scan had to be repeated because of poor quality for only 5 patients, resulting in a mean radiation dose of $16 \mu \mathrm{Sv}$ per patient. This lower dose of HR-QCT as compared with the dose of a CT scan of the hand/wrist (16 compared with $46 \mu \mathrm{Sv}$ ) can be explained by the fact that the length of the scanned region with HR-pQCT covers only $30.6 \mathrm{~mm}$ at the level of the scaphoid bone, whereas CT covers the scaphoid bone, the distal part of the radius, and all carpal bones. Accordingly, the effective radiation dose of HR-pQCT is very low compared with CT but can be interpreted as equal if the length of the scanned region is taken into account.

In previous studies, we found that HR-pQCT is a feasible and reliable technique for scaphoid fracture diagnosis ${ }^{29}$, with "almost perfect" interobserver agreement (Fleiss kappa, 0.91) according to the guidelines by Landis and $\mathrm{Koch}^{35}$. In the present
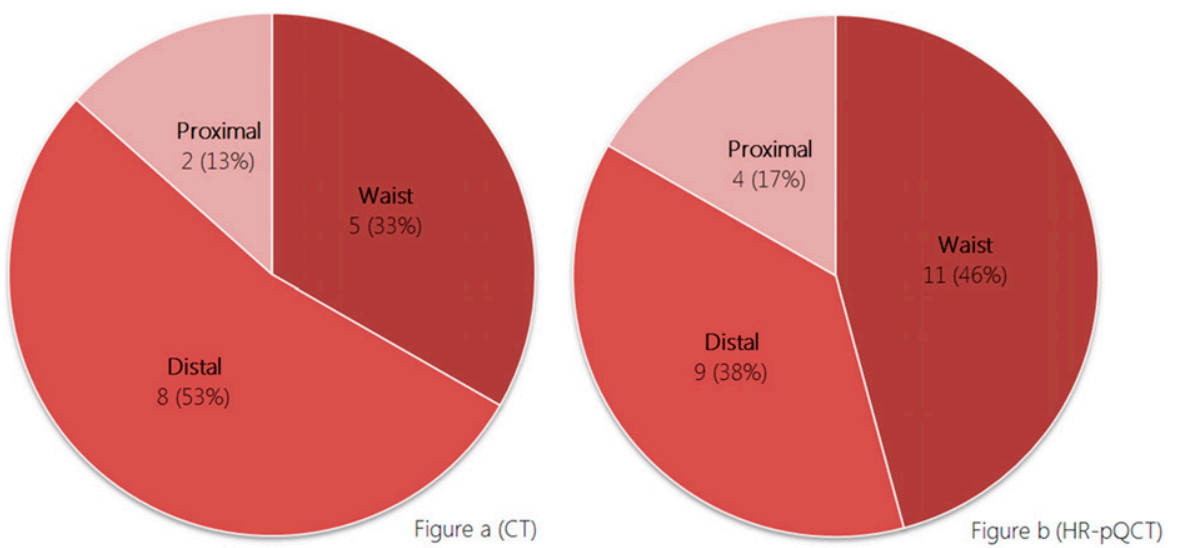

Fig. 7

Pie chart showing the scaphoid fracture location assessment on CT (Fig. 7-A) and HR-pQCT (Fig. 7-B) $($ W = 0.955). 
The Journal of Bone \& Joint Surgery · Jbjs.org Volume 102-A · Number 24 - December 16, 2020
Improved Detection of Scaphoid Fractures with HR-pQCT Compared With Conventional CT study, the number of patients diagnosed with a scaphoid fracture was 60\% higher when using HR-pQCT as compared with CT.

In agreement with previous studies ${ }^{8,50,51}$, our data showed male predominance and relatively young age in patients with scaphoid fractures. We found no difference in mechanism of injury between patients with a scaphoid fracture, with another type of fracture, and without a fracture in the present study. Regarding scaphoid fracture location, previous studies of adults have demonstrated that scaphoid waist fractures are the most common, inconsistently followed by proximal ${ }^{4,33,52}$ and distal ${ }^{53-55}$ fractures. In the present study, the most common fractures were type-A1 (tubercle) fractures based on CT and type-A2 fractures based on HR-pQCT (Figs. 6-A and 6-B). This finding implies that HR-pQCT detects more clinically relevant fractures. As a result of the relatively small numbers, no hard conclusions can be drawn on this topic yet.

The present study is limited by the lack of a true reference standard; one of the important challenges in diagnosing scaphoid fractures is the development of such a standard. In the present study, we compared a novel technique (HR-pQCT) with an existing technique (CT) for scaphoid fracture detection and found that HR-pQCT detects scaphoid fractures that CT does not. These findings are promising but need to be replicated in other studies, and further research should address the clinical consequences of scaphoid fractures that are missed on CT and investigate the costeffectiveness of HR-pQCT. Although the implementation of HRpQCT is achievable in daily practice as the scanning time for the scaphoid is only 6 minutes, HR-pQCT is currently used for research purposes and substantial processing time is required. In our facility, the costs of an HR-pQCT scan are roughly 3 times higher than the costs of a regular CT scan. On the basis of current developments related to high-resolution scanners, standard protocols for scanning the scaphoid will be developed and image processing and analysis time will most likely be reduced in the near future. The availability of HR-pQCT scanners worldwide remains a limitation. Another limitation of our study is the lack of assessment of intraobserver variability as the observers only assessed the scans once. The present study is strengthened by the relatively large cohort of patients with a clinically suspected scaphoid fracture. Moreover, all included patients underwent both CT and HR-pQCT on the same day.

In conclusion, scaphoid fracture detection is superior with HR-pQCT in comparison with CT. The number of patients with a diagnosed scaphoid fracture was $60 \%$ higher when using
HR-pQCT as compared with CT. HR-pQCT could be a promising new application for the detection of scaphoid fractures.

A.M. Daniels, $\mathrm{MD}^{1,2}$

M.S.A.M. Bevers, $\mathrm{MSc}^{3}$

S. Sassen, $\mathrm{MD}^{1}$

C.E. Wyers, $\mathrm{PhD}^{1,2,4}$

B. van Rietbergen, $\mathrm{PhD}^{3,5}$

P.P.M.M. Geusens, $\mathrm{MD}, \mathrm{PhD}^{4,5}$

S. Kaarsemaker, $\mathrm{MD}^{1}$

P.F.W. Hannemann, $\mathrm{MD}, \mathrm{PhD}^{4}$

M. Poeze, $\mathrm{MD}, \mathrm{PhD}^{2,4}$

J.P. van den Bergh, $\mathrm{MD}, \mathrm{PhD}^{1,2,4,6}$

H.M.J. Janzing, $\mathrm{MD}, \mathrm{PhD}^{1}$

${ }^{1}$ Departments of Surgery (A.M.D. and H.M.J.J.), Radiology (S.S.), Internal Medicine (C.E.W. and J.P.v.d.B.), and Orthopedic Surgery (S.K.), VieCuri Medical Centre, Venlo, the Netherlands

${ }^{2}$ NUTRIM School for Nutrition and Translational Research in Metabolism, Maastricht University, Maastricht, the Netherlands

${ }^{3}$ Orthopedic Biomechanics, Department of Biomedical Engineering, Eindhoven University of Technology, Eindhoven, the Netherlands

${ }^{4}$ Departments of Internal Medicine (C.E.W., P.P.M.M.G., and J.P.v.d.B.) and Surgery and Trauma Surgery (P.F.W.H. and M.P.), Maastricht

University Medical Centre, Maastricht, the Netherlands

${ }^{5}$ Department of Orthopedic Surgery, Research School CAPHRI, Maastricht University, Maastricht, the Netherlands

${ }^{6}$ Faculty of Medicine, Hasselt University, Belgium

Email address for A.M. Daniels: adaniels@viecuri.nl

ORCID iD for A.M. Daniels: 0000-0002-3228-0954

ORCID iD for M.S.A.M. Bevers: 0000-0003-4036-2017

ORCID iD for S. Sassen: 0000-0001-8985-195X

ORCID iD for C.E. Wyers: 0000-0001-7662-3990

ORCID iD for B. van Rietbergen: 0000-0002-2278-2934

ORCID iD for P.P.M.M. Geusens: $\overline{0000-0002-7547-9146}$

ORCID iD for S. Kaarsemaker: 0000-0001-8811-4464

ORCID iD for P.F.W. Hannemann: 0000-0003-1861-4329

ORCID iD for M. Poeze: 0000-0001-5005-1285

ORCID iD for J.P. van den Bergh: 0000-0003-3984-2232

ORCID iD for H.M.J. Janzing: 0000-0002-0195-5840

\section{References}

1. Tiel-van Buul MM, van Beek EJ, Broekhuizen AH, Bakker AJ, Bos KE, van Royen EA. Radiography and scintigraphy of suspected scaphoid fracture. A long-term study in 160 patients. J Bone Joint Surg Br. 1993 Jan;75(1):61-5.

2. Beeres FJ, Rhemrev SJ, Hogervorst M, den Hollander P, Jukema GN. [Scaphoid fractures: diagnosis and therapy]. Ned Tijdschr Geneeskd. 2007 Mar 31;151(13): 742-7. Dutch.

3. van der Molen AB, Groothoff JW, Visser GJ, Robinson PH, Eisma WH. Time off work due to scaphoid fractures and other carpal injuries in the Netherlands in the period 1990 to 1993. J Hand Surg Br. 1999 Apr;24(2):193-8.

4. Kozin SH. Incidence, mechanism, and natural history of scaphoid fractures. Hand Clin. 2001 Nov;17(4):515-24.
5. Taljanovic MS, Karantanas A, Griffith JF, DeSilva GL, Rieke JD, Sheppard JE. Imaging and treatment of scaphoid fractures and their complications. Semin Musculoskelet Radiol. 2012 Apr;16(2):159-73. Epub 2012 May 30.

6. Divelbiss BJ, Adams BD. Electrical and ultrasound stimulation for scaphoid fractures. Hand Clin. 2001 Nov;17(4):697-701, x-xi.

7. Dias JJ, Singh HP. Displaced fracture of the waist of the scaphoid. J Bone Joint Surg Br. 2011 Nov;93(11):1433-9.

8. Jenkins PJ, Slade K, Huntley JS, Robinson CM. A comparative analysis of the accuracy, diagnostic uncertainty and cost of imaging modalities in suspected scaphoid fractures. Injury. 2008 Jul;39(7):768-74. Epub 2008 Jun 9. 
The Journal of Bone \& Joint Surgery $\cdot$ JbJS. org Volume 102-A · Number 24 - December 16, 2020
Improved Detection of Scaphoid Fractures with HR-pQCT Compared With Conventional CT
9. Cheung GC, Lever CJ, Morris AD. X-ray diagnosis of acute scaphoid fractures. J Hand Surg Br. 2006 Feb;31(1):104-9. Epub 2005 Oct 28.

10. Lozano-Calderón S, Blazar P, Zurakowski D, Lee SG, Ring D. Diagnosis of scaphoid fracture displacement with radiography and computed tomography. J Bone Joint Surg Am. 2006 Dec;88(12):2695-703.

11. Mallee WH, Wang J, Poolman RW, Kloen P, Maas M, de Vet HC, Doornberg JN. Computed tomography versus magnetic resonance imaging versus bone scintigraphy for clinically suspected scaphoid fractures in patients with negative plain radiographs. Cochrane Database Syst Rev. 2015 Jun 5;6:CD010023.

12. Adey L, Souer JS, Lozano-Calderon S, Palmer W, Lee SG, Ring D. Computed tomography of suspected scaphoid fractures. J Hand Surg Am. 2007 Jan;32(1): 61-6.

13. Ring D, Lozano-Calderón S. Imaging for suspected scaphoid fracture. J Hand Surg Am. 2008 Jul-Aug;33(6):954-7.

14. Rhemrev SJ, Beeres FJ, van Leerdam RH, Hogervorst M, Ring D. Clinical prediction rule for suspected scaphoid fractures: a prospective cohort study. Injury. 2010 Oct;41(10):1026-30.

15. Karl JW, Swart E, Strauch RJ. Diagnosis of occult scaphoid fractures: a costeffectiveness analysis. J Bone Joint Surg Am. 2015 Nov 18;97(22):1860-8.

16. Memarsadeghi M, Breitenseher MJ, Schaefer-Prokop C, Weber M, Aldrian S, Gäbler C, Prokop M. Occult scaphoid fractures: comparison of multidetector CT and MR imaging -initial experience. Radiology. 2006 Jul;240(1):169-76.

17. de Zwart AD, Beeres FJ, Rhemrev SJ, Bartlema K, Schipper IB. Comparison of $\mathrm{MRI}, \mathrm{CT}$ and bone scintigraphy for suspected scaphoid fractures. Eur J Trauma Emerg Surg. 2016 Dec;42(6):725-31. Epub 2015 Nov 10.

18. Buijze GA, Jørgsholm P, Thomsen NO, Bjorkman A, Besjakov J, Ring D. Diagnostic performance of radiographs and computed tomography for displacement and instability of acute scaphoid waist fractures. J Bone Joint Surg Am. 2012 Nov 7; 94(21):1967-74.

19. Rhemrev SJ, Ootes D, Beeres FJ, Meylaerts SA, Schipper IB. Current methods of diagnosis and treatment of scaphoid fractures. Int J Emerg Med. 2011 Feb 4;4:4. 20. De Zwart AD, Beeres FJ, Ring D, Kingma LM, Coerkamp EG, Meylaerts SA, Rhemrev SJ. MRI as a reference standard for suspected scaphoid fractures. Br J Radiol. 2012 Aug;85(1016):1098-101.

21. Rhemrev SJ, de Zwart AD, Kingma LM, Meylaerts SA, Arndt JW, Schipper IB, Beeres FJ. Early computed tomography compared with bone scintigraphy in suspected scaphoid fractures. Clin Nucl Med. 2010 Dec;35(12):931-4.

22. Yin ZG, Zhang JB, Kan SL, Wang XG. Diagnosing suspected scaphoid fractures: a systematic review and meta-analysis. Clin Orthop Relat Res. 2010 Mar;468(3): 723-34. Epub 2009 Sep 15.

23. Gemme $S$, Tubbs R. What physical examination findings and diagnostic imaging modalities are most useful in the diagnosis of scaphoid fractures? Ann Emerg Med. 2015 Mar;65(3):308-9. Epub 2014 Dec 2.

24. Carpenter CR, Pines JM, Schuur JD, Muir M, Calfee RP, Raja AS. Adult scaphoid fracture. Acad Emerg Med. 2014 Feb;21(2):101-21.

25. Link TM. Osteoporosis imaging: state of the art and advanced imaging. Radiology. 2012 Apr;263(1):3-17.

26. Burghardt AJ, Krug R, Majumdar S. High-resolution imaging techniques for bone quality assessment. In: Feldman D, Pike JW, Bouillon R, Giovannucci E, Goltzman D, Hewison M, editors. Vitamin D. 4th ed. Academic Press; 2018. p 1007-41.

27. de Jong JJA, Arts JJC, Willems PC, Bours SPG, Bons JPA, Menheere PPCA, van Rietbergen B, Geusens PP, van den Bergh JPW. Contra-lateral bone loss at the distal radius in postmenopausal women after a distal radius fracture: a two-year follow-up HRpQCT study. Bone. 2017 Aug;101:245-51. Epub 2017 May 11.

28. de Jong JJA, Heyer FL, Arts JJC, Poeze M, Keszei AP, Willems PC, van Rietbergen $\mathrm{B}$, Geusens PP, van den Bergh JPW. Fracture repair in the distal radius in postmenopausal women: a follow-up 2 years postfracture using HRpQCT. J Bone Miner Res. 2016 May;31(5):1114-22. Epub 2016 Jan 5.

29. Bevers MSAM, Daniels AM, Wyers CE, van Rietbergen B, Geusens PPMM, Kaarsemaker S, Janzing HMJ, Hannemann PFW, Poeze M, van den Bergh JPW. The feasibility of high-resolution peripheral quantitative computed tomography (HRpQCT) in patients with suspected scaphoid fractures. J Clin Densitom. 2019 Aug 16. [Epub ahead of print].

30. Pichler W, Windisch G, Schaffler G, Heidari N, Dorr K, Grechenig W. Computerassisted 3-dimensional anthropometry of the scaphoid. Orthopedics. 2010 Feb; 33(2):85-8.

31. Manske SL, Zhu Y, Sandino C, Boyd SK. Human trabecular bone microarchitecture can be assessed independently of density with second generation HRpQCT. Bone. 2015 Oct;79:213-21. Epub 2015 Jun 14.

32. Pialat JB, Burghardt AJ, Sode M, Link TM, Majumdar S. Visual grading of motion induced image degradation in high resolution peripheral computed tomography: impact of image quality on measures of bone density and micro-architecture. Bone. 2012 Jan;50(1):111-8. Epub 2011 Oct 13.

33. Luria S, Schwarcz Y, Wollstein R, Emelife P, Zinger G, Peleg E. 3-dimensional analysis of scaphoid fracture angle morphology. J Hand Surg Am. 2015 Mar;40(3): 508-14. Epub 2015 Jan 9.

34. Herbert TJ, Fisher WE. Management of the fractured scaphoid using a new bone screw. J Bone Joint Surg Br. 1984 Jan;66(1):114-23.

35. Daniels AM, Wyers CE, Janzing HMJ, Sassen S, Loeffen D, Kaarsemaker S, van Rietbergen B, Hannemann PFW, Poeze M, van den Bergh JP. The interobserver reliability of the diagnosis and classification of scaphoid fractures using highresolution peripheral quantitative CT. Bone Joint J. 2020 Apr;102-B(4):478-84. 36. Ilica AT, Ozyurek S, Kose O, Durusu M. Diagnostic accuracy of multidetector computed tomography for patients with suspected scaphoid fractures and negative radiographic examinations. Jpn J Radiol. 2011 Feb;29(2):98-103. Epub 2011 Feb 27.

37. Beeres FJ, Rhemrev SJ, den Hollander P, Kingma LM, Meylaerts SA, le Cessie S, Bartlema KA, Hamming JF, Hogervorst M. Early magnetic resonance imaging compared with bone scintigraphy in suspected scaphoid fractures. J Bone Joint Surg Br. 2008 Sep;90(9):1205-9.

38. Buijze GA, Mallee WH, Beeres FJ, Hanson TE, Johnson WO, Ring D. Diagnostic performance tests for suspected scaphoid fractures differ with conventional and latent class analysis. Clin Orthop Relat Res. 2011 Dec;469(12):3400-7. Epub 2011 Sep 30.

39. Low G, Raby N. Can follow-up radiography for acute scaphoid fracture still be considered a valid investigation? Clin Radiol. 2005 Oct;60(10):1106-10.

40. Munk B, Frøkjaer J, Larsen CF, Johannsen HG, Rasmussen LL, Edal A, Rasmussen LD. Diagnosis of scaphoid fractures. A prospective multicenter study of 1,052 patients with 160 fractures. Acta Orthop Scand. 1995 Aug;66(4):359-60.

41. Tiel-van Buul MM, van Beek EJ, Broekhuizen AH, Nooitgedacht EA, Davids PH, Bakker AJ. Diagnosing scaphoid fractures: radiographs cannot be used as a gold standard! Injury. 1992;23(2):77-9.

42. Jacobsen $S$, Hassani G, Hansen D, Christensen 0 . Suspected scaphoid fractures. Can we avoid overkill? Acta Orthop Belg. 1995;61(2):74-8.

43. Müller R, Hahn M, Vogel M, Delling G, Rüegsegger P. Morphometric analysis of noninvasively assessed bone biopsies: comparison of high-resolution computed tomography and histologic sections. Bone. 1996 Mar;18(3):215-20.

44. Pistoia W, van Rietbergen $B$, Lochmüller EM, Lill CA, Eckstein F, Rüegsegger $P$. Image-based micro-finite-element modeling for improved distal radius strength diagnosis: moving from bench to bedside. J Clin Densitom. 2004 Summer; 7(2): 153-60.

45. Macneil JA, Boyd SK. Bone strength at the distal radius can be estimated from high-resolution peripheral quantitative computed tomography and the finite element method. Bone. 2008 Jun;42(6):1203-13. Epub 2008 Feb 13.

46. Varga P, Pahr DH, Baumbach S, Zysset PK. HR-pQCT based FE analysis of the most distal radius section provides an improved prediction of Colles' fracture load in vitro. Bone. 2010 Nov:47(5):982-8. Epub 2010 Aug 6.

47. Mueller TL, Christen D, Sandercott S, Boyd SK, van Rietbergen B, Eckstein F, Lochmüller EM, Müller R, van Lenthe GH. Computational finite element bone mechanics accurately predicts mechanical competence in the human radius of an elderly population. Bone. 2011 Jun 1;48(6):1232-8. Epub 2011 Mar 2.

48. van Rietbergen $B$, Ito $K$. A survey of micro-finite element analysis for clinical assessment of bone strength: the first decade. J Biomech. 2015 Mar 18;48(5): 832-41. Epub 2014 Dec 18.

49. de Jong JJ, Willems PC, Arts JJ, Bours SG, Brink PR, van Geel TA, Poeze M, Geusens PP, van Rietbergen B, van den Bergh JP. Assessment of the healing process in distal radius fractures by high resolution peripheral quantitative computed tomography. Bone. 2014 Jul;64:65-74. Epub 2014 Apr 2.

50. Van Tassel DC, Owens BD, Wolf JM. Incidence estimates and demographics of scaphoid fracture in the U.S. population. J Hand Surg Am. 2010 Aug;35(8):1242-5.

51. Böhler L, Trojan E, Jahna H. The results of treatment of 734 fresh, simple fractures of the scaphoid. J Hand Surg Br. 2003 Aug;28(4):319-31.

52. Schaefer M, Siebert HR. [Fracture of the semilunar bone]. Unfallchirurg. 2002 Jun;105(6):540-52; quiz 52-3. German.

53. Brøndum V, Larsen CF, Skov $O$. Fracture of the carpal scaphoid: frequency and distribution in a well-defined population. Eur J Radiol. 1992 Sep;15(2):118-22.

54. Dias J, Kantharuban S. Treatment of scaphoid fractures: European approaches. Hand Clin. 2017 Aug;33(3):501-9.

55. Dias JJ, Wildin CJ, Bhowal B, Thompson JR. Should acute scaphoid fractures be fixed? A randomized controlled trial. J Bone Joint Surg Am. 2005 Oct; $87(10): 2160-8$. 